\title{
Multi-dimensional Analysis of the Theory of Life Safety in Physical Education
}

\author{
Sanying Peng ${ }^{1, a^{*}}$ and Shuguang Fang ${ }^{2, b}$ \\ ${ }^{1}$ Department of Physical Education, Changzhou Campus of Hohai University, \\ Changzhou City, 213022, Jiangsu Province, China \\ ${ }^{2}$ Department of Physical Education, Changzhou Institute of Technology, Changzhou City, 213002, \\ Jiangsu Province, China \\ aemail:pengsy1979@163.com, bemail:994810892@qq.com
}

Keywords: Physical Education; Life Safety Education; Theoretical Analysis; Humanism

\begin{abstract}
This paper is based on theoretical literature of life safety education and aims to demonstrate its significance through multidimensional analysis on philosophy, economics and politics. A completed set of theoretical framework for life safety education will be figured out and conducted to Physical Education in schools. It turns out that the significance of life safety is emphasized and illustrated in different theories, like Humanism in philosophy, demand theory in economics, right consciousness and equalis value in politics, which provide a solid theoretical foundation for the implementation of life safety education in phisical education.
\end{abstract}

\section{Introduction}

The life existence and maintenance is the logical starting point for physical education and the top priority to ensuring the existence and maintenance of life. School Physical Education will incorporate life-safety education and school physical resources, which have been applied to carry out education in the first aid skills and danger prevention skills, focus on "people first" philosophy, and students are regarded as ordinary individuals in the social development and the basic dignity of life for students has been emphasized.

Marx's rational thoughts of humanism philosophy should be followed who presents a rational philosophy, as the individuals in the complex relationships," the nature of human life is to survive, the realization form of human survival lies in living, and life and living are the direct manifestation of the individual life ontology of philosophical anthropology, reasonable survival of human beings, healthy development and freedom as well as liberation are the pursuits of principles of value in 
anthropology of Marx's humanism philosophy. "[1]. A "people-oriented" and continuous life safety education system should be carried out in school physical education in student body movement operational level.

\section{Theoretical Analysis of Life Safety Education in School Physical Education}

In philosophy, the lives of individual students should be regarded as basis and life safety education should be carried out throughout physical education. Human beings are by far the world's only animal able to carry out the purposeful and conscious activities, they not only take the initiative to understand the objective world, but also recognize themselves as objects, and also take the initiative to transform and understand their subjective world. Therefore, humans are the world's most valuable, and researchers must start from the understanding of human before having an understanding of the world. Human beings should be regarded as the basis of the world, and it is necessary to regard the life safety as the basis in the implementation of life safety education in physical teaching.

The reason for that human beings is the basis of this world is that human beings can put everything in the world as a personal attribute, and the reason for that the world belongs to human beings is that the world is not just for the human beings, but also can be used and transformed by human beings. Only human beings have this kind of magic power, and human transformation of the world is not without purpose, unconscious, but to aim at meeting the needs of human beings on purpose. In addition, human needs are endless, and human development is endless, namely, the driving force of the human transformation is endless and inexhaustible.

Just because of this, it is necessary to adhere to the people-oriented principle, and students will receive endless power in the process of carrying out the life safety education in physical education. The completely opposite situation for the human-centered philosophy is called "alienation"

phenomenon [2]. Therefore, to adhere to the human-centered principle in philosophy, researchers must oppose to the alienation for human beings in real life and stick to the dominant position of life safety education in school physical education. Whether it is physical education class or other classes have been confronted with the same situation. According to some media reports, some schools force students to participate in physical fitness test regardless of their physical conditions, which is extremely inappropriate.

In economy, demand theory is the basis of the life safety education in physical education. The main part of economic production is human beings, and the aim must be based on people's needs, then the implementation of life safety education in school physical education is required to take the 
requirements of students in the first place. Just take Xiamen University for an example, the university regards tree climbing as part of physical education curriculum, which has caused a lot of criticism. Some people hold the opinion that universities students ignore their own duties, but in the opinion of the author, tree climbing is what the life safety education courses lack in the contemporary college and physical education curriculum can make up this lesson, which is worth being promoted widely. Once the flood hits, researchers can see that even the animals know to climb a tree to save themselves in a lot of flood disaster scenes, but people have no ability and no consciousness to rely on natural conditions to escape from danger, which is a serious consequence of safety education lacking in the educational process.

Second, researchers must consider the resource and labor saving problems in the implementation of life safety education and eliminate waste problem. Waste is the ills of the country, which may have close relationship with the vanity culture, and researchers have no reason not to response the appealing of the party and the country. Therefore, researchers should consider the benefits and the feelings of others, so researchers can understand how to do in the end.

Finally, researchers should consider the harmonious development with nature in the implementation within the curriculum. Researchers have to consider the local conditions and cannot artificially create or destroy nature. In reality, researchers will find that such sports programs as directional movement have been implemented in mountains, which would have been able to exercise and train students' ability to escape, but some student have no consciousness to protect the environment and even destroy the environment, leading to the serious destruction to the environment. Meanwhile, other people cannot carry out the same course, namely, some students just meet their own needs and undermine others' needs, it is not conducive to sustainable development, and this is unacceptable.

In politics, the life right of individual student should be respected. "Human" and "people" are different concepts in the connotation and denotation, and the two sides cannot be identical, but in the socialist society, "people" are the major existing form of groups of "human". Therefore, from the perspective of politics, interpretation of "human-oriented" is the same as that for "people-oriented", which can be illustrated that people should be regarded as basis, so that people can be the real masters of the country.

The theory is applied to life safety education in physical course, and the right to receive the life safety education in physical education should be respected for individual students, which shouldn't be replaced. 
For example, many schools and units still just focus on the exam and college entrance examination, and physical education class will be replaced by general knowled ge classes just before examination. Therefore, the students will not get physical exercise and body building, which is common in real education and must be corrected. In fact, there are numerous examples as the above mentioned, it can be seen that researchers show the indifference to life to a great extent in the process of carrying out life safety education. The examination-oriented and GDP-oriented school education system should be changed. Life is precious and is worth treasuring throughout one's life, just as the saying goes, "where there is life there is hope yet," even if researchers do not cherish the green hill of life, how to sustain firewood of life? Sports course should assume the responsibility to completely eradicate the infringements of endangering life safety. Physical education class should also assume responsibility to cultivate students to have courage and boldness, which should be promoted in the whole society.

From the perspective of ethics and morals, students are regarded as human beings, and such life safety education should be carried out in physical education. According to the human nature theory of Marxism, human nature is the unification of the group nature, social nature and the individual nature. Human beings are not only regarded as a member of the group and the social group, but also as individuals with unique personalities. Human beings are regarded as the personality existence, and its nature is self-uniqueness. From this point, people are specific individuals, and each individual has thus apart from others. "From the perspective of space, the individual is unique; from the perspective of time, individuals are non-repetitive; from the perspective of existence value, individuals are irreplaceable and equivalence "[3], and from this layer, people-oriented thought requires the respect for each individual member of society regardless of the individual's economic attributes and class attribute, which has a unique value. Each individual should be given due respect, they are the people-oriented objects.

From the perspective of school education, it is necessary to adhere to the people-oriented principle and respect students in the implementation of life safety education of physical education. Each student has the deserved rights and each student's legitimate life safety interests should be protected and respected. The interests of individual students cannot be damaged for the sake of group interests or other interests.

In addition, on the premise of emphasizing consistent fundamental interests of different subjects, it should be noted that inconsistencies between the interests of different subjects and the conflict and opposition between the interests of different subjects still exist. And there is also no exception in the implementation of student life safety education at the school. 
And how to coordinate this inconsistency to maintain the safety of the fundamental interests of all groups of students as much as possible is an important task faced by the contemporary Chinese schools, which is also the core idea of understanding people-oriented principle and building a socialist harmonious society.

\section{Conclusions}

In summary, the adherence to such two principles as "human-oriented" and "throughout life" are the most basic principles and the bottom line and the basic norms of education from the perspective of philosophy, economy, politics as well as ethics and morals for the school education, especially for physical education field, which reflect the importance of life's basic human rights and are interest safeguard for groups of students. These theories have become the theoretical foundation for carrying out life safety education in physical education in schools.

\section{References}

[1] Qin L. life'S Characteristics: the starting point of school sports' life perspective [J], 201 1, Journal of sports, $18(11): 9-14$.

[2]Central Compilation and Translation Bureau of China. Karl Marx and Frederick Engels (volume 49) [M]. Beijing: people's press, 1982.

[3]Han QX, Zhang HCH. People-oriented- from content to people [M]. Nanjing: Jiangsu people's press, 2006.

[4] Weng Y. The research about present situation and countermeasure of implementing life safety education during Shanghai middle school physical education [D]. Shanghai: east China normal university, 2011.

[5]Wang F, Yang XQ, Mu SHH, Lu D. The value of school sports education based on Life safety demands [J]. Journal of sportS, 2012, 12 (1) : 80.

[6] Miao QM. Theory of Marx's humanistic philosophy application: care of life, survival and life attitude - and their philosophical basis [J]. Journal of i Kunming College, 2009, 3 (4) : 11 - 4.

[7]S un XM. The classification of the sports teaching materials and processing under the view of Life safety education [J]. Journal of Chinese school sports, 2009, (5) : 12. 
[8] Zhang ZHY.Sports and Personality Education [J].Shandong Institute of Physical Education, 2011,27 (2): 33-35.

[9] Yang FY.Study on the Safety Education in the Primary and Secondary Education during social Transition Period[J]. Journal of Tianzhong, 2012,2 (26): 132.

[10]Wang ZP,Shun XM.Construction of School Sports Life Safety Education System in China[J]. Journal of Sports, 2012,19 (5): 93-95. 